\title{
Retraction: Temporary ditches are effective in reducing soil erosion in hilly areas. An evaluation with the RUSLE model
}

\author{
Rosa Francaviglia, Ulderico Neri \\ Council for Agricultural Research and Economics (CREA), Research Centre for Agriculture and \\ Environment, Rome, Italy
}

To:

Pier Paolo Roggero, Editor-in-Chief, Italian Journal of Agronomy, and Michele Moscato, PAGEPress Publications, Publisher

We take note of your communication following the report by Dr. Paolo Bazzoffi regarding the copyright infringement of the paper 'Effectiveness of the GAEC cross-compliance standard short-term measures for runoff water control on sloping land (temporary ditches and grass strips) in controlling soil erosion' (Authors: Bazzoffi, Ciancaglini, Laruccia), that can be found at the following address: https://www.agronomy.it/index.php/agro/ article/view/ija.2011.6.s1.e3.

The title of the retracted publication is: 'Temporary ditches are effective in reducing soil erosion in hilly areas. An evaluation with the RUSLE model' (Authors: Francaviglia, Neri), that can be found at the following address: https://www.agronomy.it/index. php/agro/article/view/1762).

The undersigned authors thoroughly agree with the points raised by Dr. Paolo Bazzoffi in relation to the copyright infringement.

In particular, we agree that the original paper 'Effectiveness of the GAEC cross compliance standard short-term measures for runoff water control on sloping land (temporary ditches and grass strips) in controlling soil erosion' was not clearly indicated as original data source in the paper 'Temporary ditches are effective in reducing soil erosion in hilly areas. An evaluation with the RUSLE model'.

We also recognize that we did not give credit to Dr. Paolo Bazzoffi of the original methodology, particularly: i) the original materials and methods; ii) the GIS elaboration; and iii) the original data and results.
The authors declare that:

- they considered the opportunity to review the data published by Dr. Bazzoffi et al. shown in Table 7 of their original publication after a data re-elaboration, as shown in Table 3 of the publication to be retracted, with the aim to provide a statistical comparison of erosion in hilly agricultural land among the Italian Regions, as well as introducing an evaluation of the weight of the parameters implemented in the RUSLE model using a multiple regression technique;

- they are aware of not having adequately recognized the copyrights of Dr. Bazzoffi and co-authors Ciancaglini and Laruccia.

For these reasons, and as requested, we retract the paper 'Temporary ditches are effective in reducing soil erosion in hilly areas. An evaluation with the RUSLE model' from publication.

We apologize to Dr. Bazzoffi, Dr. Ciancaglini and Dr. Laruccia for the unpleasant inconvenience caused.

We also take the opportunity to thank Dr. Paolo Bazzoffi for coordinating the EFFICOND and MONACO projects, in which we participated in various work packages, offering the possibility of a valuable and constructive work experience.

Sincerely,

Rosa Francaviglia and Ulderico Neri
Correspondence: Ulderico Neri, Council for Agricultural Research and Economics (CREA), Research Centre for Agriculture and Environment, via della Navicella 2-4, 00184 Rome, Italy.

E-mail: ulderico.neri@crea.gov.it

(C) Copyright: the Author(s), 2021

Licensee PAGEPress, Italy

Italian Journal of Agronomy 2021; 16:1960

doi:10.4081/ija.2021.1960

This article is distributed under the terms of the Creative Commons Attribution Noncommercial License (by-nc 4.0) which permits any noncommercial use, distribution, and reproduction in any medium, provided the original author(s) and source are credited. 